\title{
Opposed Flame Spread over Cylindrical PMMA Under Oxygen-Enriched Microgravity Environment
}

\author{
Chuanjia Wu, Shuangfeng Wang* and Feng Zhu, Key Laboratory of \\ Microgravity, Institute of Mechanics, Chinese Academy of Sciences, \\ Beijing, China
}

Chuanjia Wu, Shuangfeng Wang and Feng Zhu, School of Engineering Science, University of Chinese Academy of Sciences, Beijing, China

Xinyan Huang, Research Center for Fire Engineering, The Hong Kong Polytechnic University, Kowloon, Hong Kong, China

Yongli Yin, China Astronaut Research and Training Center, Beijing, China

Received: 1 March 2019/Accepted: 1 August 2019

\begin{abstract}
The enriched oxygen ambient may be applied to China's next generation space station. To understand the fire behaviors under oxygen-enriched microgravity environment, flame-spread experiments on extruded poly(methyl)methacrylate (PMMA) rods with $10-\mathrm{mm}$ diameter were conducted in the SJ-10 Satellite. The opposed flame-spread behaviors were studied at the oxygen-enriched ambient $(33.5 \%$ and $49.4 \%$ ) under low flow velocities in the range of 0 to $12 \mathrm{~cm} / \mathrm{s}$. After the ignition in the middle of the sample, an opposed flame spread was achieved, rather than the forward flame spread. The flame-spread rate increases with the opposed flow velocity, due to the decreased flame width and the enhanced flame heat flux. Moreover, a blue flame sheet with a frequent burst of bubbles is found throughout the opposed-flow spread process, showing a near extinction behavior. For the oxygen concentration above $25 \%$, normal-gravity experiments suggest that whether PMMA is cast or extruded should have a negligible effect on the opposed flame spread in microgravity. Compared to normal gravity, the microgravity flame spread rate in the oxygen-enriched atmosphere is slower which is the order of $0.1 \mathrm{~mm} / \mathrm{s}$, only one-tenth to onefifth of that in normal gravity at the same nominal opposed flow velocity, and the acceleration of flame spread in microgravity by increasing oxygen concentration is also much smaller. This result suggests that (1) if the environmental gas flow is small, the fire hazard increased by raising oxygen level in microgravity space cabin can be much smaller than that on Earth; and (2) the fire risk of oxygen-enriched microgravity environment might be overestimated when a ground-based test method is employed to evaluate the burning characteristics of solid material.
\end{abstract}

Keywords: Spacecraft fire safety, Blue flame, Cast and extruded PMMA, Thermally-thick fuel, Extinction

\footnotetext{
* Correspondence should be addressed to: Shuangfeng Wang, E-mail: sfwang@imech.ac.cn
} 


\section{Introduction}

Fire safety has always been a challenge for human-crew space missions, especially during a long mission [1]. To improve the safety of spacecraft, it is important to understand the fire behaviors in these special space-travel environmental conditions, such as microgravity, low airflow, reduced pressure, and high oxygen $\left(\mathrm{O}_{2}\right)$ level [2]. Because of the limited number, duration and scale of existing microgravity experiments, there are still many unknowns particularly about the fire behaviors of thermally-thick fuels as well as the related phase-change processes.

Space agencies have been considering the use of reduced pressure (55 to $70 \mathrm{kPa}$ ) with elevated $\mathrm{O}_{2}$ concentrations $\left(X_{O_{2}}=27\right.$ to $\left.32 \mathrm{vol} \%\right)$ as the ambient of space stations. The lower ambient pressure releases the mechanical stress of space cabin and reduces the preparation time needed to prevent decompression sickness in extra-vehicular activity [3]. The flammability of solids and flame spread rates are often used to characterize the material fire risk. However, it is well-known that the oxygen-enriched environment can lead to a larger fire risk. So far, most long-duration microgravity experiments in the spacecraft or space station are conducted under normal or low $\mathrm{O}_{2}$ levels $[2,4-6]$ to study the limiting $\mathrm{O}_{2}$ concentration (LOC) $[7,8]$ and how much the fire risk will increase in the microgravity environment is still not understood quantitatively.

Previously, researchers have investigated the steady combustion and flame spread over thick cylindrical solid fuels experimentally in normal-gravity environments $[9,10]$. Using axial symmetric cylindrical sample to study the opposed flame spread can avoid the edge effect. Inside the spacecraft, there are many cylindrical components, such as cable and wires, which are serious fire safety concerns [11, 12] and inspired several theoretical and experimental studies [12-14]. For example, Salva and Juste [14] carried out low-gravity experiments in KC-135 aircraft laboratory and showed that the flame spread rate on thin PMMA rods (diameters of 1 to $2.5 \mathrm{~mm}$ ) decreases with the increased rod diameter and reduced oxygen concentration. Tarifa et al. [13] used a PMMA rod with $4 \mathrm{~mm}$ external diameter and $2 \mathrm{~mm}$ inner diameter and found that the flame spread rates in normal gravity are larger than in reduced gravity, and the difference between results at normal gravity and at reduced gravity increases when the oxygen concentration increases. Furthermore, many microgravity flame-spread experiments have been conducted for thin electrical wires, as reviewed in [8]. However, whether a similar trend will occur to the thick cylindrical fuel is still unknown.

Recently, the long-duration ( $>1 \mathrm{~min}$ ) microgravity flame-spread experiments were conducted with thermally-thick PMMA rods in the International Space Station (ISS) as part of the BASS-II project [5]. The flame-spread phenomena were studied under low opposed flow velocities ranging from $0.4 \mathrm{~cm} / \mathrm{s}$ to $8 \mathrm{~cm} / \mathrm{s}$ and low $X_{O 2}(15$ to $21 \%)$. Experimental results showed that at $X_{O 2}<20 \%$, flame spread in microgravity could be faster than in normal gravity, and the LOC in microgravity is lower. These results suggest that under certain environmental conditions there could be a higher fire risk and a more difficult fire suppression in microgravity than on Earth. In addition, the blue flame was observed near both 
low-flow extinction and high-flow blow off [15]. So far, the opposed flame spread behaviors in microgravity and higher $\mathrm{O}_{2}$ concentration are still unclear for thermally-thick cylindrical fuels.

For thermoplastic fuels, the phase-change process, including melting, dripping, and re-condensation can play an important role in the flame spread [16]. For PMMA fuel, whether is made by cast or extrude significantly changes the flame spread behaviors, because of the degree of polymerization and phase-change process $[10,17]$. On normal-gravity Earth, it has been found that the downward dripping flow can control the downward (opposed) flame spread rate [10, 18-20]. Comparatively, there is no dripping phenomenon in microgravity, but the molten fuel may accumulate into a ball which can grow larger [21, 22]. It is expected that in microgravity the liquid-phase Marangoni convection heating may become more important in driving the flame spread over thermoplastics. Nevertheless, there is almost no study addressing the effect of melting on flame spread in microgravity, posing a knowledge gap. Therefore, extruded PMMA cylinders were chosen in the design of SJ-10 microgravity experiments.

The present work aims to further understand the flame-spread behaviors under oxygen-enriched microgravity environment as well as to gain insight into the controlling mechanisms of flame spreading against a forced oxidizer flow over rod samples. The microgravity experiments aboard the SJ-10 Satellite of China [23, 24] were conducted to study the behaviors of flame spread over extruded PMMA rods at a high $X_{O 2}(33.5 \%$ and $49.4 \%)$ and small opposed flow $\left(V_{g} \leq 12 \mathrm{~cm} / \mathrm{s}\right)$. To facilitate the analysis, normal gravity tests were also carried out to compare with microgravity data.

\section{Experimental}

\subsection{Microgravity Experiments}

Microgravity experiments were conducted using the flight payload for the space experiment "Ignition and Burning of Solid Materials in Microgravity" aboard the Chinese SJ-10 Satellite in April 2016 [24, 25] (Fig. 1a). The microgravity test chamber in the SJ-10 Satellite included eight wind tunnels (Fig. 1b, c) with a size of $95 \mathrm{~mm} \times 95 \mathrm{~mm} \times 120 \mathrm{~mm}$, and the effective volume of test chamber was 39 L. Among the eight flow tunnels, 8 solid samples (2 PMMA rods, 5 PMMA plates, and 1 HDPE plate) were fixed on each tunnel respectively, and two experiments with PMMA rods were reported in this paper. A schematic of the flow tunnel, together with details on the experimental procedures can be found in $[25,26]$.

The cylindrical fuel sample was made of extruded clear PMMA with a diameter of $10 \mathrm{~mm}$ and a length of $69 \mathrm{~mm}$, as illustrated in Fig. 1d. Comparatively, cylindrical rods in BASS-II experiments had similar diameters of 6.4 , 9.5, and $12.7 \mathrm{~mm}$, while the sample was made of cast black PMMA [5]. It should be noted that although cast and extruded PMMA were used respectively, their thermophysical properties are almost the same [27]. The sample was fixed at its two ends by a specially designed sample holder to make sure that the sample was parallel to the flow. Five R-type thermocouples were embedded inside the PMMA, and their 
(a)

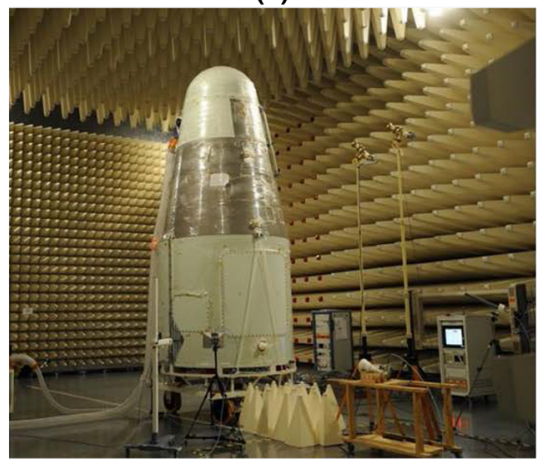

(c)

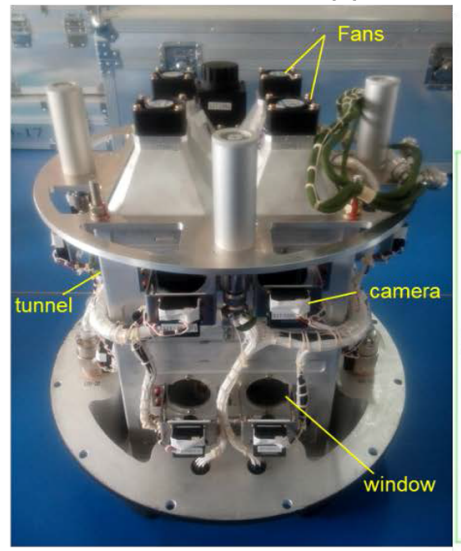

(b)

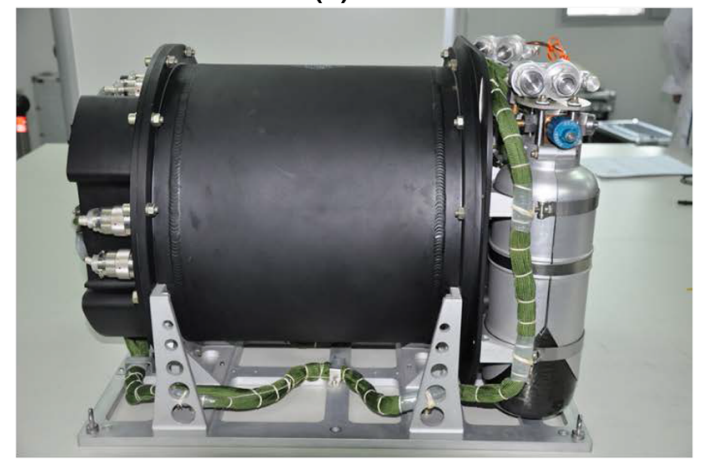

(d)
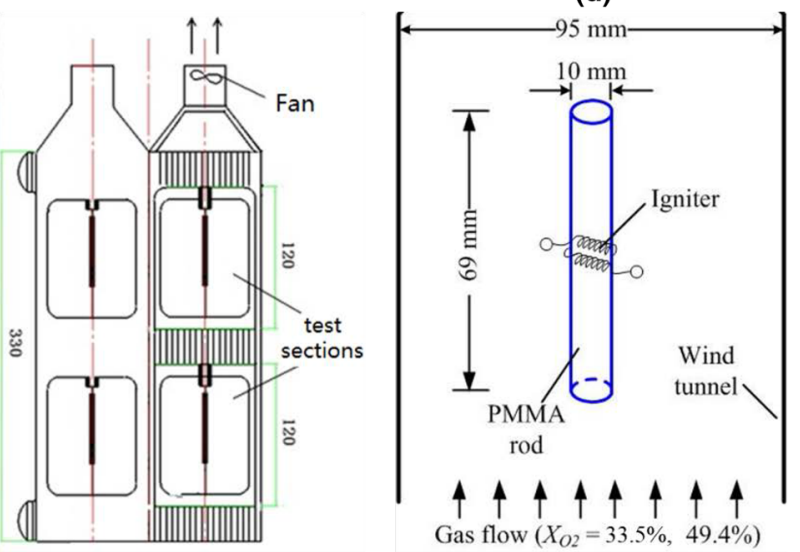

Gas flow $\left(X_{O 2}=33.5 \%, 49.4 \%\right)$

\section{Figure 1. a SJ-10 recoverable satellite (http://www.cas.cn/zt/kjzt) sjshkxsywx/), b combustion test chamber, c wind tunnels and test sections inside the chamber, and d diagram of the test section for PMMA rod.}

beads with a diameter of $75 \mu \mathrm{m}$ were positioned on 1-mm above the fuel surface to help locate the flame leading edge. A circular igniter made of resistant wire was placed surrounding the center of the sample to ensure good contact with the fuel and a successful ignition. The total resistance of igniter was $7 \mathrm{ohms}$, and the supply power was $28 \mathrm{~V}$, which was set to provide a heating power of $112 \mathrm{~W}$ for $20 \mathrm{~s}$.

A fan was installed at the downstream end of the tunnel to produce the opposed gas flow with a velocity between $0 \mathrm{~cm} / \mathrm{s}$ and $12 \mathrm{~cm} / \mathrm{s}$. A gas control system was integrated into the flight hardware to supply $\mathrm{O}_{2}-\mathrm{N}_{2}$ mixtures to the test chamber and vent out the residual gas. During the microgravity experiments, the pressure, $\mathrm{O}_{2}$ concentration, and temperature of the test chamber were continuously monitored by different sensors. A digital color CCD camera (WATEC WAT230 G3.8) recorded the side view of the ignition and flame-spread processes through the observation window on the tunnel wall. The recording rate of the 
camera was at 25 frames per second, and the video resolution was $752 \times 582$ pixel.

The two PMMA rod samples were tested at the ambient $\mathrm{O}_{2}$ concentration $\left(X_{\mathrm{O} 2}\right)$ of $33.5 \%$ and $49.4 \%$, respectively. Note that these two $\mathrm{O}_{2}$ concentrations were much higher than the range of $15 \%$ to $21 \%$ in the past BASS-II experiments in ISS [5]. Prior to each test, the residual gas in the test chamber was first vented out to the vacuum of outer space. Then, the test chamber was filled with the $\mathrm{O}_{2}-\mathrm{N}_{2}$ mixture to create an oxygen-enriched atmosphere under the standard ambient pressure of $101 \mathrm{kPa}$. After the gas-filling process, the fan of the wind tunnel started to operate to facilitate the mixing of $\mathrm{O}_{2}$ and $\mathrm{N}_{2}$ and to produce an initial opposed flow velocity of $12 \mathrm{~cm} / \mathrm{s}$ around the PMMA rod sample. Such a pre-flow process lasted for $510 \mathrm{~s}$ (Stage III in Fig. 7), so the gas mixture was sufficiently mixed, and the gas flow through wind tunnel was stabilized. Afterward, the igniter was energized in the middle of PMMA rod to initiate the flame spread. After the flame spreading for a period, the opposed flow velocity was reduced to $9 \mathrm{~cm} / \mathrm{s}$, $6 \mathrm{~cm} / \mathrm{s}$, and eventually to 0 , similar to the procedure of BASS-II tests $[5,6]$. The duration of each test is listed in Table 1. It should be noted that experiments at $X_{\mathrm{O} 2}=33.5 \%$ were first performed. Referencing to the theoretical model by Ref. [12] for cylindrical rod and the limited microgravity experimental results for PMMA plate [28], the duration of the first test was preset. According to the results from the first experiments, the duration of the test at $X_{\mathrm{O} 2}=49.4 \%$ was modified before the experiment.

All experimental data were directly transmitted from SJ-10 Satellite to the ground receiver. Data process based on the video reveals that the durations were long enough for the flame to reach a new steady-stage spread under the change of the opposed flow velocity. The pressure of the 39-L test chamber had a minor increase of about $1 \mathrm{kPa}$ after the test, and the final value of $X_{O 2}$ decreased less than $2 \%$ (absolute value) from $33.5 \%$ to $32.7 \%$ and from $49.4 \%$ to $47.9 \%$, respectively. Since such small changes are not expected to have a significant influ-

\section{Table 1}

\section{The Time Durations and Flow Velocities in the Microgravity Flame Spread Tests and Flame-Spread Rates (FSR) in Microgravity and Normal-Gravity}

\begin{tabular}{lccll}
\hline $\begin{array}{l}\text { Oxygen level } X_{\mathrm{O} 2} \\
(\%)\end{array}$ & $\begin{array}{c}\text { Flow velocity } V_{g} \\
(\mathrm{~cm} / \mathrm{s})\end{array}$ & $\begin{array}{c}\text { Duration (Space) } \\
t(\mathrm{~s})\end{array}$ & $\begin{array}{c}\text { FSR (Space) } \\
(\mathrm{mm} / \mathrm{s})\end{array}$ & $\begin{array}{c}\text { FSR (Earth) } V_{f} \\
(\mathrm{~mm} / \mathrm{s})\end{array}$ \\
\hline 33.5 & 12 & 65 & 0.125 & 0.565 \\
& 9 & 35 & 0.091 & 0.542 \\
& 6 & 60 & 0.074 & 0.559 \\
49.4 & 0 & 750 & Extinct after $28 \mathrm{~s}$ & - \\
& 12 & 50 & 0.330 & 1.405 \\
& 9 & 60 & 0.187 & 1.364 \\
& 6 & $>750$ & Extinct after $25 \mathrm{~s}$ & - \\
\hline
\end{tabular}


ence, the flame can be regarded as spreading under essentially constant ambient conditions. In addition, according to Video (1-1) and (1-2), during the flame spread process, the shape of the flame structure is stable, and from Fig. 8, the linear position-time plot shows that a constant flame spread rate for each given flow velocity. This is another evidence that the small changes in oxygen concentration and chamber pressure have little effect on flame spread behaviors. These raw data are presented in the "Appendix" section.

\subsection{Normal Gravity Experiments}

The normal gravity experiments were conducted to compare with microgravity experiments and support the data analysis. The normal-gravity experimental apparatus was similar to that in $[5,15]$. It was mainly composed of two parts: (1) a test section made of a vertical quartz glass tube with a diameter of $90 \mathrm{~mm}$ and a total length of $400 \mathrm{~mm}$, and (2) a flow homogenizer section filled with aluminum honeycomb and glass beads to smooth the flow. To be consistent with the microgravity test, premixed $\mathrm{O}_{2}-\mathrm{N}_{2}$ gases with $X_{O 2}$ ranging from $21.0 \%$ to $49.4 \%$ (relative error $<2 \%$ ) were used. The flow rate of the mixture was metered by a sonic orifice before entering the homogenizer section, such that the flow velocity in the test section could range from $2 \mathrm{~cm} / \mathrm{s}$ to $250 \mathrm{~cm} / \mathrm{s}$ (relative error $<2 \%$ ).

In order to evaluate the influence of melting and dripping, both cast and extruded PMMA rods with the same diameter of $10 \mathrm{~mm}$ and a length of $74 \mathrm{~mm}$ were tested. The rod sample had hemispherical ends to minimize the flow disturbance, and it was supported at the bottom end by a thin stainless-steel bar and fixed at the axis of the test section. After the top end of the rod was ignited by a torch, the flame spread downward while premixed $\mathrm{O}_{2}-\mathrm{N}_{2}$ gases were flowing upward. A digital camera was used to record the side view of the flame. All tests were repeated at least three times to reduce random error. The uncertainty on the measured flame spread rate is mainly due to the ambiguity of flame leading edge with a calculated error of $6 \%$.

\section{Results and Discussion}

\subsection{Flame Behaviors}

Figure 2 shows the images of spreading flames over extruded PMMA rod in microgravity $\left(X_{O_{2}}=33.5 \%\right.$ and $\left.49.4 \%\right)$ under three opposed flow velocities of 12,9 , and $6 \mathrm{~cm} / \mathrm{s}$, compared with normal-gravity flame spread with the same ambient conditions. After a strong ignition process in the middle of sample (Fig. 2a), a stable opposed flame spread, rather than a forward flame spread, in microgravity was achieved. This phenomenon is similar to that for flame spread over PMMA sheet when ignited in the middle of the sample [26]. This finding also supports the postulation of Prasad et al. [29] that flame can only spread over thermally-thick solid fuels in the opposed mode since fuel does not burnout beneath the flame established over thick solid fuels. As the flame spread away from the igniter, the igniter stayed in good contact with sample. Based on the fact that heat 
(a) Microgravity ignition process

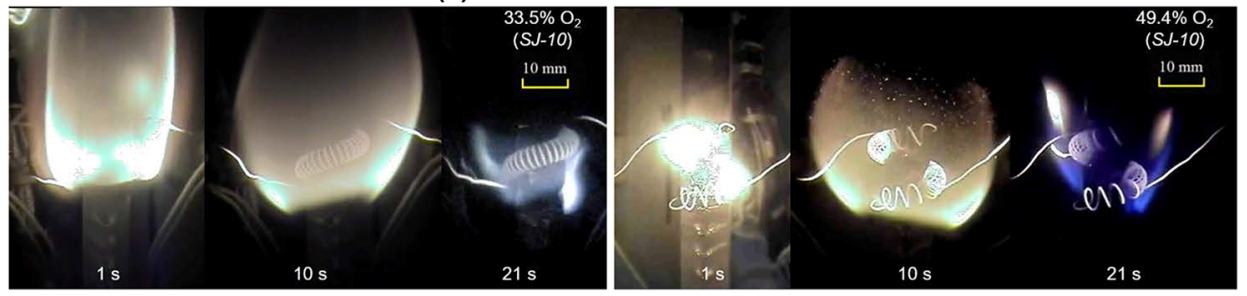

(b) SJ-10 and BASS-II Microgravity flame spread in $33.5 \%$ and $18.2 \% \mathrm{O}_{2}$

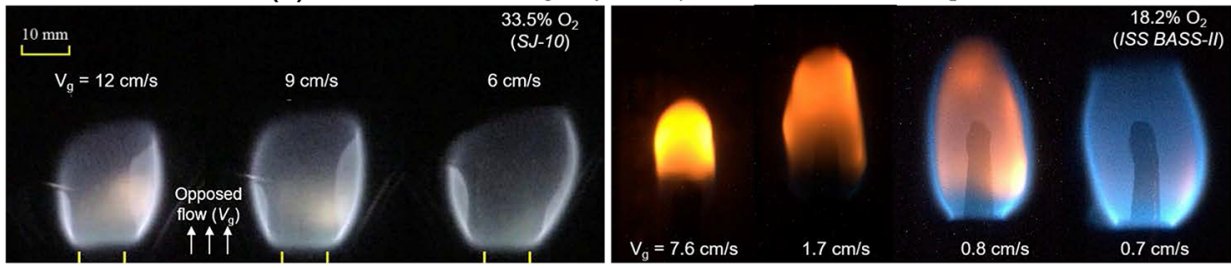

(c) SJ-10 Microgravity flame spread in $49.4 \% \mathrm{O}_{2}$

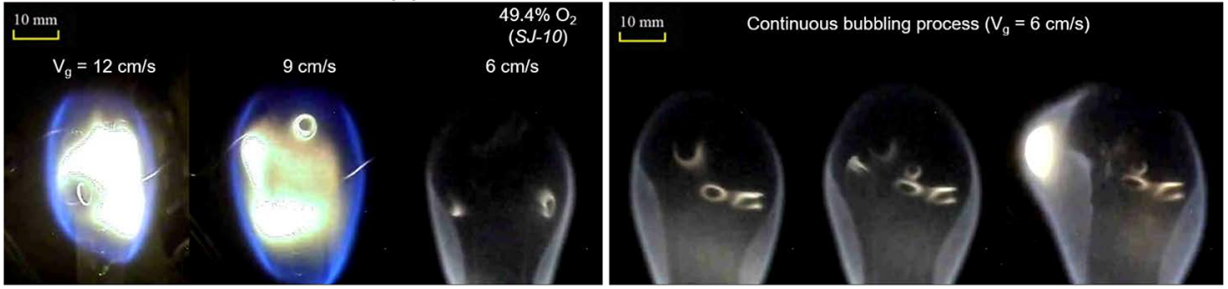

(d) Normal-gravity flame spread on Earth

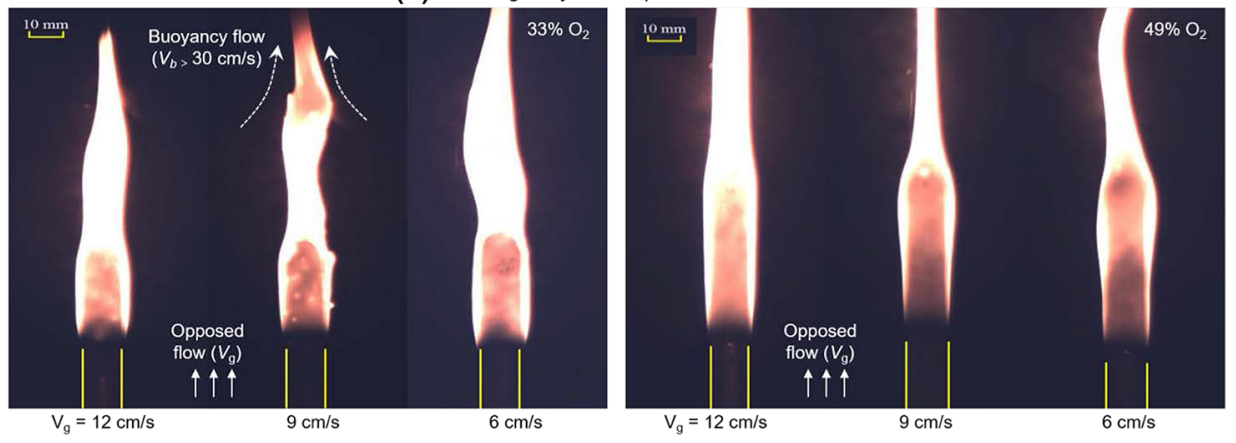

Figure 2. Photographs of a ignition process of $10-\mathrm{mm}$ thick extruded PMMA rod in SJ-10 Satellife, b microgravity flame spread under different opposed flow velocities ( $\left.X_{02}=33.5 \%\right)$ compared with lowoxygen BASS-II fests [5], c microgravity flame spread ( $\left.X_{02}=49.4 \%\right)$ with continuous bubbling process, and d normal-gravity flame spread on Earth. The yellow lines reflect the position of the rods. The raw videos are included in Online Appendix (Color figure online).

conduction from the flame to the solid is the main driving force of flame spread for opposed spreading flames, attention is mainly focused on the flame leading edge, so although the igniter always locates downwards of the flame, it had a neg- 
ligible effect on the flame leading edge upstream. The flame tip was blocked by the downstream part of the sample, and the tip was always open. Also, the shape of flame structure agrees with the classical Burke-Schumann solution for under-ventilated diffusion flame in absent of gravity [30, 31].

Moreover, at the oxygen-enriched atmosphere and low-velocity flow, the appearances of flame are significantly different between microgravity and normal gravity. The microgravity flame is short and blue, and the flame width increases as the opposed flow is reduced. Comparatively, the normal-gravity flame is long and yellow, and the flame width is insensitive to small opposed flow velocity because a much larger upward buoyancy flow $\left(V_{b}>30 \mathrm{~cm} / \mathrm{s}\right)$ dominates over the applied opposed flow. The complete videos of flame spread over both rod samples in microgravity and representative normal-gravity experiments can be found in Online Appendix.

For both microgravity experiments at high $\mathrm{O}_{2}$ concentrations, the flame was yellow during the ignition process initiated by the resistant heater. After turning off the heater, the flame became pale blue at $X_{O_{2}}=33.5 \%$ throughout the rest of spreading process (Fig. 2b). At $X_{O_{2}}=49.4 \%$, the outer flame sheet was bright blue, while the internal was bright yellow because of a strong and frequent bubbling process (Fig. 2c). The burst of bubbles on the fuel surface injected a large amount of fuel (both fuel vapor gases and tiny droplets), which created a local fuel-rich mixture and multiple small yellow flamelets. Such bubble-bursting behavior was also observed in the cast PMMA rod of BASS-II test, but the frequency was much lower. Comparatively, the bubble-bursting behavior of the current extruded PMMA rod is more frequent and continuous throughout the flamespread process.

This blue-flame phenomenon also is different from the past BASS-II experiments in low $\mathrm{O}_{2}$ levels $\left(X_{O 2}=15 \%\right.$ to $21 \%$ ), as compared in Fig. $2 \mathrm{~b}$. At $X_{O_{2}}=$ $18.2 \%$ and the opposed flow velocity above $1 \mathrm{~cm} / \mathrm{s}$, the flame is yellow and bright [5]. Only when the opposed flow velocity decreases below $1 \mathrm{~cm} / \mathrm{s}$, a similar blue and open-tip flame occurs, showing a near-extinction behavior. Nevertheless, regardless of the $\mathrm{O}_{2}$ concentration, flame extinguishes when the opposed flow is absent in microgravity $\left(V_{g}=0\right)$, and a blue flame occurs near the low-flow-velocity extinction.

Generally, the PMMA flame is always yellow on Earth, as found from the normal-gravity experiment in Fig. 2d. As the $\mathrm{O}_{2}$ concentration increases, the flame becomes hotter and brighter. Since the yellow color of the flame is primarily a result of soot radiation, a brighter yellow flame indicates a higher-concentration of soot particles standing on the hot flame sheet. In normal gravity, a blue flame only occurs near the extinction limit, such as at low pressure [32], low $\mathrm{O}_{2}$ concentration and high flow speed (near blow-off) [15] or in the localized premixed flame region $[33,34]$. The observed blue flame at microgravity and high $\mathrm{O}_{2}$ concentration in Fig. 2b, c indicates a lower soot concentration in the flame or potential soot standing away from hotter regions [35]. One possible explanation is that the limited oxygen supply helps to reduce soot precursors and soot in fuel-rich regions, so that complete oxidation occurred in fuel-lean regions [33, 34]. 
One necessary condition for such low-flow extinction is that the flame heat flux $\left(\dot{q}_{f}^{\prime \prime}\right)$ cannot produce sufficient pyrolysis gases from the fuel, which may be expressed as

$$
\dot{q}_{f}^{\prime \prime}=k_{g} \frac{T_{f}-T_{p y}}{\delta_{f}}+\dot{q}_{f, r}^{\prime \prime}<\dot{q}_{s, r}^{\prime \prime}+\dot{m}_{c r t}^{\prime \prime} \Delta H_{p y}
$$

where subscript $f, g, s$, and $r$ represents flame, gas, solid, and radiation, respectively; $\delta_{f}$ is the flame stand-off distance; $\dot{m}_{c r t}^{\prime \prime}$ is the critical mass flux of pyrolysis gas to sustain a diffusion flame; $\Delta H_{p y}$ is the heat of pyrolysis; $T_{f}$ and $T_{p y}$ are the flame temperature and the fuel pyrolysis temperature, respectively.

Previously, such low-flow extinction has been termed by some researchers as "radiation extinction" [36-38] if the importance of radiation loss $\left(\dot{q}_{s, r}^{\prime \prime}\right)$ from both flame sheet and fuel surface is emphasized; and "oxygen-transport limited regime" [39] if the increase of flame standoff distance $\left(\delta_{f}\right)$ is emphasized. Nevertheless, the change in flame color and shape, as well as the sensitivity to $\mathrm{O}_{2}$ concentration, further indicates a strong change in flame chemistry and flame radiation near this extinction limit. Thus, we may define such low-flow extinction as the "DiffusionRadiation (Chemical) extinction."

The comparison between ISS BASS-II and SJ-10 experiments suggests that at the higher $\mathrm{O}_{2}$ concentration, the opposed flame spread enters the Diffusion-Radiation (Chemical) Regime in a larger critical opposed flow velocity. Specifically, such critical opposed velocity is larger than $12 \mathrm{~cm} / \mathrm{s}$ for $X_{O 2}>33 \%$, while is about $1 \mathrm{~cm} / \mathrm{s}$ for $X_{O 2}<21 \%$. There are two possible explanations:

(1) The critical condition for Diffusion-Radiation (Chemical) Regime is that the $\mathrm{O}_{2}$ diffusion velocity becomes comparable to the opposed flow velocity. Then, part of the $\mathrm{O}_{2}$ leaks through downstream to create a partially premixed blue flame. The $\mathrm{O}_{2}$ diffusion velocity increases with the $\mathrm{O}_{2}$ concentration, so the required opposed flow velocity is larger.

(2) At a high $\mathrm{O}_{2}$ concentration, the flame sheet moves toward the oxygen stream, and a smaller amount of fuel vapor is required to maintain the minimum reaction rate of the flame, resulting in a fuel-lean and soot-free flame.

To further explain such flame behaviors, numerical simulations with detailed chemical kinetics are required.

\subsection{Opposed Flame-Spread Rate}

The rate of flame spread in microgravity is acquired by tracking the flame leading edge position on the PMMA rod from the recorded video, which is also verified by the thermocouple measurement on the fuel surface. Shortly after the opposed flow velocity is varied, a semi-steady-state flame spread is quickly achieved, and the raw data for the time history of the flame position is shown in Fig. 8. Table 1 lists all measured microgravity FSR in SJ-10 and compares with the normal-gravity flame-spread rate on Earth. Figure $3 \mathrm{a}$ plots the flame-spread rate of extruded 

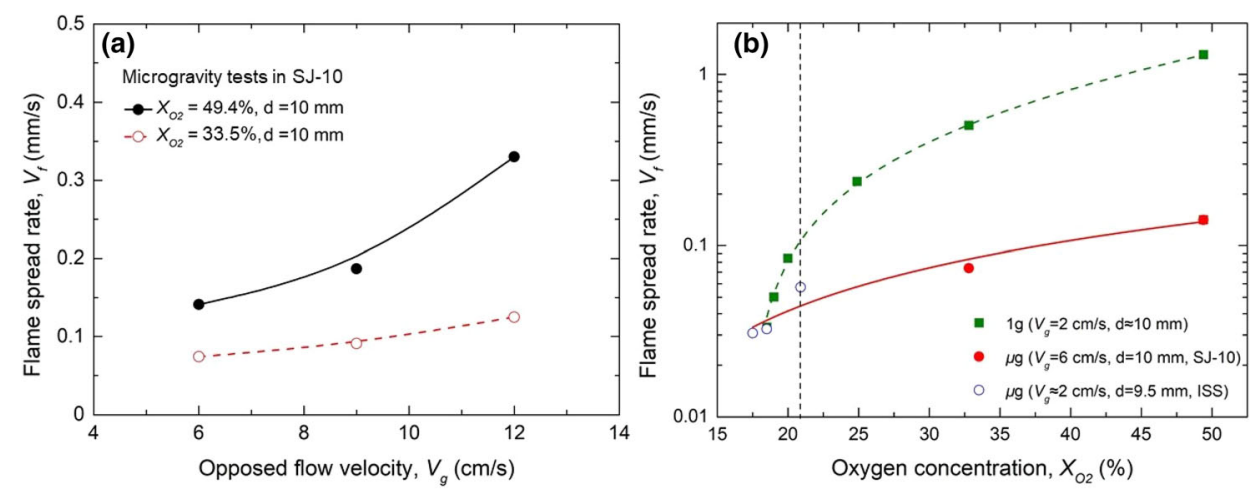

\section{Figure 3. Microgravity flame-spread rate in SJ- 10 (extruded PMMA) as a function of a opposed flow velocily, and $b \mathrm{O}_{2}$ concentration, compared with normal-gravity data and ISS BASS-II data [5] where the dashed line indicates the normal air with $21 \% O_{2}$ (uncertainties of the flame spread rate for each data point are below $6 \%$ ).}

PMMA as a function of the opposed flow velocity in microgravity. Specifically, in microgravity, as the opposed flow velocity increases from $6 \mathrm{~cm} / \mathrm{s}$ to $12 \mathrm{~cm} / \mathrm{s}$, the flame-spread rate increases from $0.074 \mathrm{~mm} / \mathrm{s}$ to $0.125 \mathrm{~mm} / \mathrm{s}$ for $X_{O 2}=33.5 \%$, and from $0.141 \mathrm{~mm} / \mathrm{s}$ to $0.330 \mathrm{~mm} / \mathrm{s}$ for $X_{O 2}=49.4 \%$, respectively.

Figure $3 \mathrm{~b}$ shows the opposed flame-spread rate as a function of $\mathrm{O}_{2}$ concentration and compares between microgravity and normal gravity. Note that the PMMA samples used in BASS-II (cast PMMA) and SJ-10 (extruded PMMA) are different, but the influence of PMMA type on flame spread rates at high $\mathrm{O}_{2}$ levels is small as discussed in detail in Sect. 3.3. Clearly, the flame-spread rate increases with $\mathrm{O}_{2}$ concentration because of the increase in flame temperature and radiation. However, in microgravity, the acceleration of flame spread by increasing $\mathrm{O}_{2}$ concentration is much smaller. That is, as $X_{O 2}$ increases from $21 \%$ to $50 \%$, the flamespread rate only increases 2 to 3 times in microgravity, while increasing more than 10 times in normal gravity. Comparatively, for the thin electrical wire with a diameter of about $1 \mathrm{~mm}$ and a hollow PMMA rod with an inner diameter of $2 \mathrm{~mm}$ and an external diameter of $4 \mathrm{~mm}$, the flame-spread rate has a similar sensitivity to the $\mathrm{O}_{2}$ concentration between normal-gravity and microgravity [13, 40]. Except for cylinder-shaped specimen, Zhu et al. [26], Olson et al. [28], West et al. [41], Altenkirch et al. [42] and Vietoris et al. [43] have used flat PMMA to investigate flame spread behavior in enriched oxygen atmosphere in microgravity. Compared to Fernandez-Pello et al. [44] where flame spread experiments were conducted for thick PMMA rods at various oxygen concentrations (in the range of $19 \% \mathrm{O}_{2}$ to $100 \% \mathrm{O}_{2}$ in volume) in normal gravity, the acceleration of flame spread rate in normal gravity is still faster than that in microgravity. This result is similar with cylinder-shaped PMMA. One possible reason is that despite the high oxygen concentration, the microgravity flame over thick PMMA rod in this work 
is still within the Diffusion-Radiation (Chemical) Regime and near extinction, because of the low opposed flow velocity.

The flame spread over solid is fundamentally a continuous piloted-ignition process [18]. For thick PMMA solids, the opposed flame-spread rate increasing with flow velocity is mainly controlled by the gas-phase heat transfer [44, 45], and it may be explained by a qualitative heat-transfer equation for the flame leading edge (or preheating zone) as

$$
V_{f} \approx \frac{\dot{q}_{f}^{\prime \prime 2} \delta_{g}}{\left(\rho_{s} c_{s} k_{s}\right)\left(T_{p y}-T_{0}\right)^{2}} \approx\left(\frac{\rho_{g} c_{g} k_{g}}{\rho_{s} c_{s} k_{s}}\right)\left(\frac{T_{f}-T_{p y}}{T_{p y}-T_{0}}\right)^{2} V_{g}
$$

where $\dot{q}_{f}^{\prime \prime} \approx k_{g}\left(T_{f}-T_{p y}\right) / \delta_{g}$ is the effectively flame heat flux to the sample surface; $\delta_{g} \approx \alpha_{g} / V_{g}=k_{g} /\left(\rho_{g} c_{g} V_{g}\right)$ is the length of preheating or diffusion; $T_{f}, T_{p y}$ and $T_{0}$ are the flame temperature, pyrolysis temperature and initial temperature of solid fuel, respectively; $k, \rho, c$, and $\alpha$ are the conductivity, density, specific heat, and thermal diffusivity, respectively.

Historically, when the flame spread process is not affected by the flame chemistry, it is often termed the "Thermal Regime" [44]. As the opposed flow velocity increases, the flame stand-off distance decreases, which is reflected by the decreasing flame width in Fig. 2b, c, resulting in a larger flame heat flux. In microgravity, the conductive heat transfer from the flame tends to dominate the preheating process, because velocities of opposed flow and diffusion are comparable (i.e., weak convection), and the blue flame indicates weak flame radiation.

Previously, the "Thermal-Regime" flame-spread behavior was observed in the ISS BASS-II experiment with black PMMA under a low $X_{O 2}(16$ to $21 \%$ ) and a very low opposed flow velocity below $2 \mathrm{~cm} / \mathrm{s}$ [5]. The current SJ-10 microgravity experiments further confirm the theory of "Thermal Regime" under $X_{O_{2}}>33 \%$ and relatively higher opposed flow velocity between $6 \mathrm{~cm} / \mathrm{s}$ and $12 \mathrm{~cm} / \mathrm{s}$, although the surface re-radiation and flame chemistry also play important roles near the low-flow extinction, as discussed in Sect. 3.1. Comparatively, under the opposed flow velocity of $7.6 \mathrm{~cm} / \mathrm{s}$ and a low oxygen concentration of $X_{O 2}=18 \%$ in BASS-II, the flame spread may already enter the "Chemical Regime" [5].

Figure 4 summarizes the dependence of microgravity flame spread rate with opposed flow velocity based on the BASS-II and SJ-10 data, where the solid lines have been supported by the experimental data and dashed lines need to verify by future experimental data. Besides quantifying the boundary of different regimes for various $\mathrm{O}_{2}$ level, a better understanding is needed for two extinction phenomena:

(1) Low-flow extinction What is the minimum flow velocity to sustain the flame? Can external radiant heating prevent the low-flow extinction?

(2) High-flow blow off Is the flame blow off in microgravity easier than in normal gravity? Also, is there also be a transition from flame spread to fuel regression in microgravity or will the flame stay in the recirculation zone of fuel in large opposed airflow [15]? 


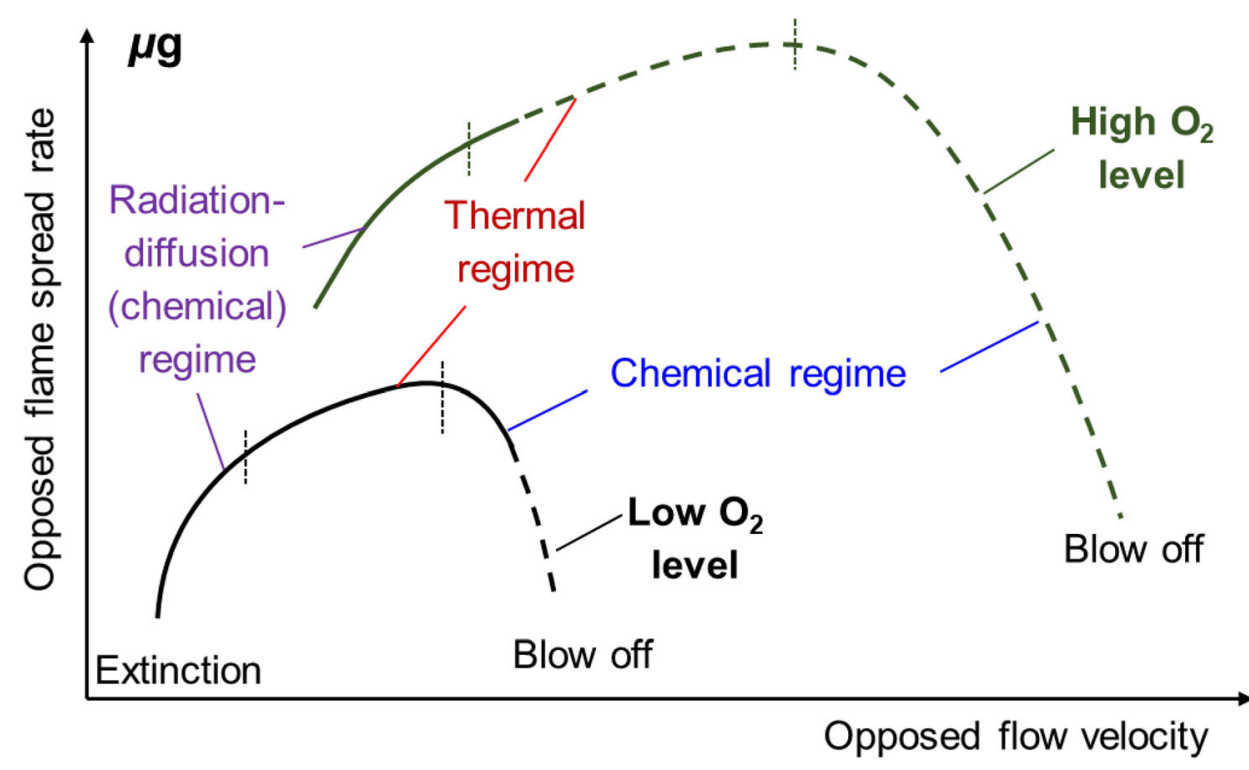

\begin{abstract}
Figure 4. A possible correlation between flame spread rates in microgravity and opposed flow velocity in low and high oxygen concentrations where the solid lines have been supported by the experimental data and dashed lines need to verify by future experimental data.
\end{abstract}

Past BASS-II experiments on similar thick PMMA rod reveals that at $X_{O 2}<$ $20 \%$, the opposed flame spread can be faster in microgravity than in normal gravity, indicating a potentially higher fire hazard in microgravity [5]. In the normal or higher $\mathrm{O}_{2}$ concentration, the flame spread in microgravity becomes slower than in normal gravity [2], and such a trend is also seen in this study. Most of past microgravity experiments on thin fuels suggest that increasing the $\mathrm{O}_{2}$ concentration, the increases of overall fire hazard will be comparable between normal gravity and microgravity [40, 46]. However, current SJ-10 experiments suggest that if the environmental gas flow is small, the fire hazard increased by rising $\mathrm{O}_{2}$ concentration in microgravity space cabin can be much smaller than that on Earth. To understand the fire risk in an oxygen-enriched spacecraft environment better, more future long-duration microgravity experiments on thick fuels are desired.

\title{
3.3. Effect of Extruded and Cast PMMA
}

Due to the limited number of satellite experiments, it was not possible to test both extruded and cast PMMA samples under many different oxygen levels. Nevertheless, the sample diameter and the gas flow rate in the current tests are very close to those in Link et al. [5]. The biggest difference between these two experiments is the type of PMMA, that is, BASS-II used the cast PMMA while SJ-10 used the extruded PMMA. If the difference between extruded or casted samples are small 
in the high oxygen level, these two experiments will have a great comparability to demonstrate the effect of oxygen concentration on flame spread rate in microgravity. Thus, we conducted ground experiments to quantify the difference in flame spread rate between the cast and extruded PMMAs.

On Earth, it has been widely observed that during flame spread, extruded PMMA will melt and drip from the sample surface, but not for cast PMMA [10, 17]. Although the cast and extruded PMMA have the same chemical formula, their different degrees of polymerization lead to a large difference in melting point, surface tension (or the tendency of bubble burst) and viscosity. The effect of melting and dripping can be indicated by how different the downward flame-spread behavior is between extruded and cast PMMA. Comparatively, in microgravity, there will be no dripping flow, so that the difference in the opposed flame spread between extruded and cast PMMA solids should be much smaller.

Figure 5 shows the downward flame-spread process over extruded PMMA on Earth under a small opposed flow of $3 \mathrm{~cm} / \mathrm{s}$ under three different $\mathrm{O}_{2}$ concentrations. Figure 6 shows the measured downward flame-spread rate for both extruded and cast PMMA rods as a function of opposed (upward) flow velocity. Because of the downward dripping flow for extruded PMMA at $X_{O 2}=21 \%$, the flame front was always attached to the fastest moving drips, that is, the flame spread rate is the dripping-flow rate. As seen in Fig. 5a and supplemental video for the normal atmosphere $\left(X_{O 2}=21 \%\right)$, a clear downward dripping flow with blue flame can be observed. In fact, the measured downward flame spread rate is the downward velocity of molten PMMA dripping flow. Such dripping flow acts as the heat source to preheat the unburnt PMMA, thus, accelerating the downward flame spread rate. As quantified in Fig. 6a, regardless of the opposed flow, the dripping flow increases at least $50 \%$ of the downward flame spread rate.

(a) $\mathrm{X}_{\mathrm{O} 2}=21 \%$

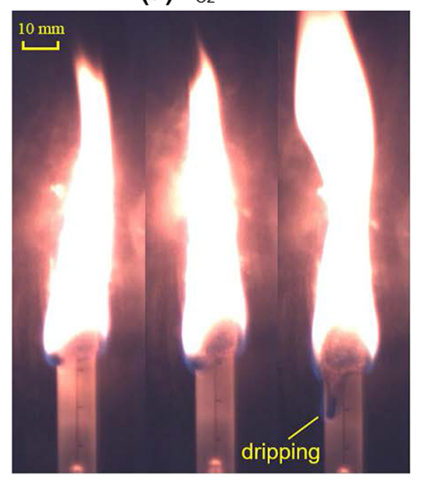

$t_{0}$

$t_{0}+10 \mathrm{~s} \quad t_{0}+20 \mathrm{~s}$

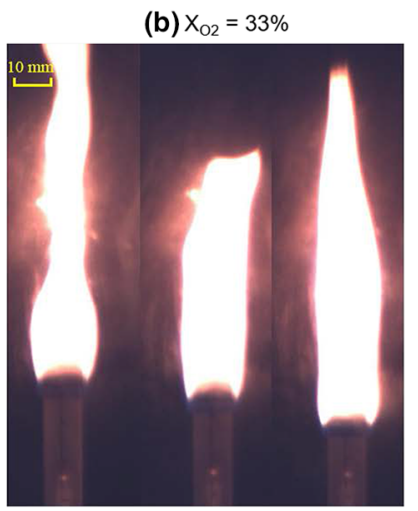

$t_{0}$ (c) $\mathrm{X}_{\mathrm{O} 2}=49 \%$

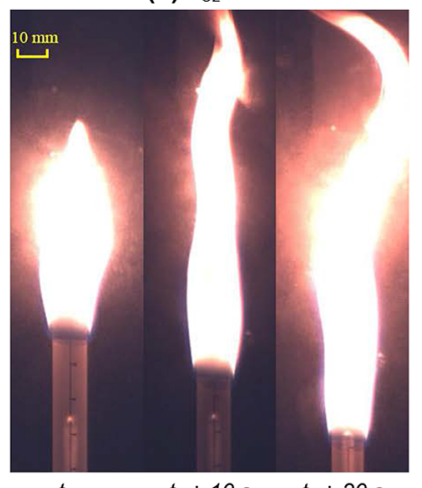

$t_{0}$

$t_{0}+10 \mathrm{~s} \quad t_{0}+20 \mathrm{~s}$

Figure 5. Normal-gravity flame-spread and dripping behaviors of extruded PMMA rod under $V_{g}=3 \mathrm{~cm} / \mathrm{s}$ and oxygen concentration $\left(X_{02}\right)$ of a $21 \%, b 33 \%$, and c 49\%. The raw videos are included in Online Appendix. 


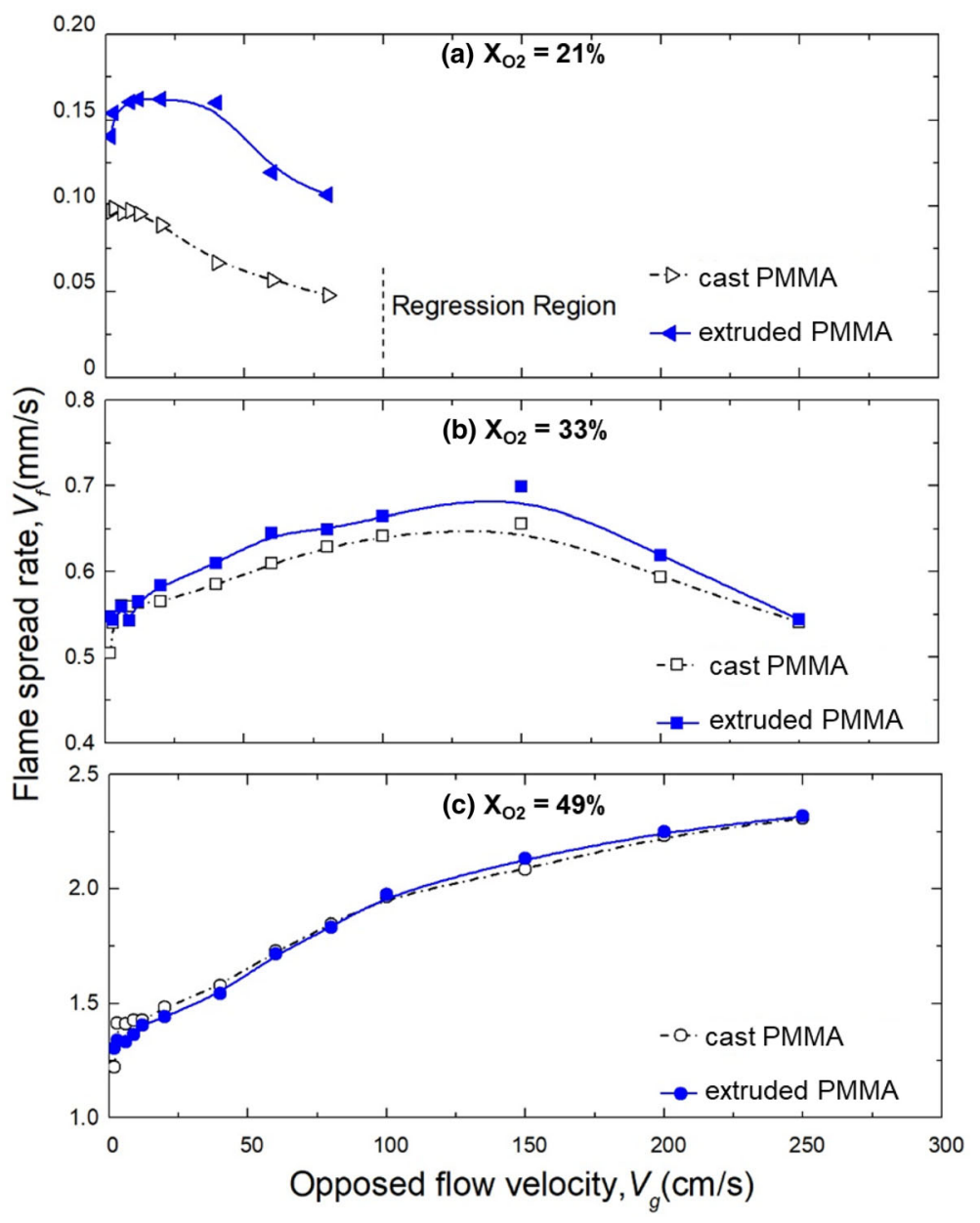

Figure 6. Downward flame spread rate over the cast and extruded PMMA rods on Earth as a function of the opposed flow velocity at the oxygen concentration $\left(X_{02}\right)$ of a $21 \%, b 33 \%$, and c $49 \%$. (uncertainties of the flame spread rates for each data point are below $6 \%)$.

In contrast, no dripping flow is observed for $X_{O_{2}}>25 \%$, as illustrated in Fig. 5b, c and supplemental video. Because of the fast flame spread, by the end of flame spread the extruded PMMA samples maintained their original shape without bending. As the oxygen concentration increases, the effective heating length of flame increases because of higher flame temperature and larger gas thermal diffusivity, and it eventually exceeds the heating length of dripping flow. Therefore, there is a negligible difference of downward flame-spread rate between cast and extruded PMMA rods, as shown in Fig. 6b, c. More importantly, these normalgravity experiments demonstrate that in microgravity, when $X_{O 2}>25 \%$, the rate 
of opposed flame spread should be very similar between extruded and cast PMMA. In other words, if cast PMMA rods were tested in the SJ-10 Satellite, very similar flame-spread data would be expected.

\section{Conclusions}

In this work, microgravity fire experiments on extruded PMMA rods with 10-mm diameter were conducted in the SJ-10 Satellite of China, and flame-spread behaviors were studied at the oxygen-enriched ambient environment $\left(X_{O 2}=33.5 \%\right.$ and $49.4 \%)$ with small-velocity flow $\left(V_{g} \leq 12 \mathrm{~cm} / \mathrm{s}\right)$. The major conclusions are as follows:

(1) After the ignition in the middle of sample, an opposed flame spread was achieved, rather than a forward flame spread. The flame spread rate increases with the opposed flow velocity, due to the decreased flame width and the enhanced flame heat flux, similar to the previous low-oxygen experiments in ISS. A blue flame sheet with a frequent burst of bubbles is found throughout the opposed-flow spread process, showing a near extinction behavior.

(2) For the $X_{O 2} \geq 25 \%$, the downward flame-spread rate in normal gravity is similar between cast and extruded PMMA samples, because the effective heating length of flame is larger than that of dripping flow. This suggests that whether the PMMA sample is cast or extruded should have a negligible effect on the opposed flame spread in microgravity.

(3) In normal ambient air $\left(X_{O_{2}}=21 \%\right)$, the opposed flame spread rate in normal gravity and microgravity are comparable. As $X_{O 2}$ increases from $21 \%$ to $50 \%$, the flame-spread rate only increases 2 to 3 times in microgravity, while increasing more than 10 times in normal gravity. In other words, not only the microgravity flame spread in the oxygen-enriched atmosphere is slower, but the acceleration of flame spread in microgravity by increasing oxygen concentration is also much smaller. This indicates that for oxygen-enriched environment, when a ground-based test method is used to evaluate the burning characteristics in microgravity, the fire risk could be overestimated.

\section{Acknowledgements}

Funding was provided by National Natural Science Foundation of China (Grant No. U1738117), Strategic Pioneer Program on Space Science of Chinese Academy of Sciences (Grant Nos. XDA04020410, XDA04020202-10).

\section{Appendix}

See Figs. 7 and 8. 
(a) $\mathrm{X}_{02}=33.5 \%$

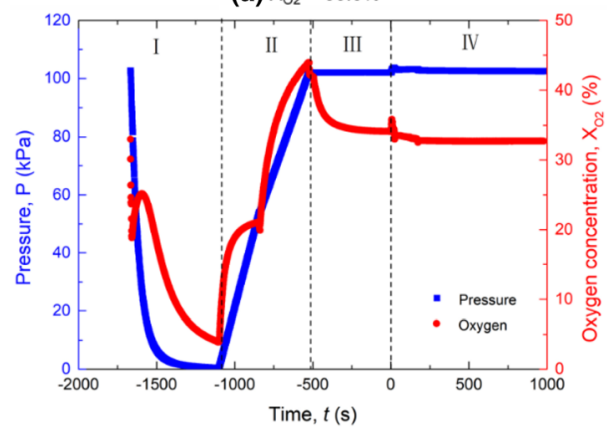

(b) $\mathrm{X}_{02}=49.4 \%$

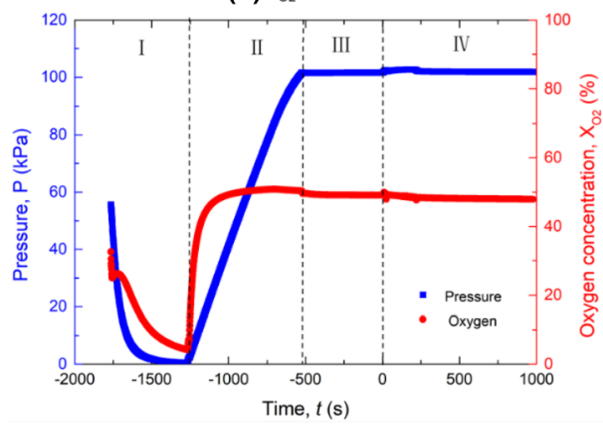

Figure 7. Time history of the chamber pressure $p$ and the chamber oxygen concentration $X_{02}$ during stages of (I) exhausting, (II) gas filling, (III) mixing, and (IV) ignition and flame spread in SJ-1 O: a $X_{02}=33.5 \%$, and $b X_{02}=49.4 \%$, where $t=0$ corresponds to the instant of ignition.

(a) $\mathrm{X}_{02}=33.5 \%$

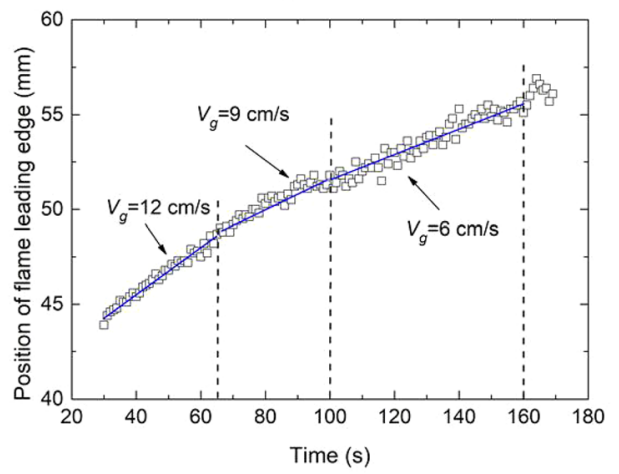

(b) $\mathrm{X}_{02}=49.4 \%$

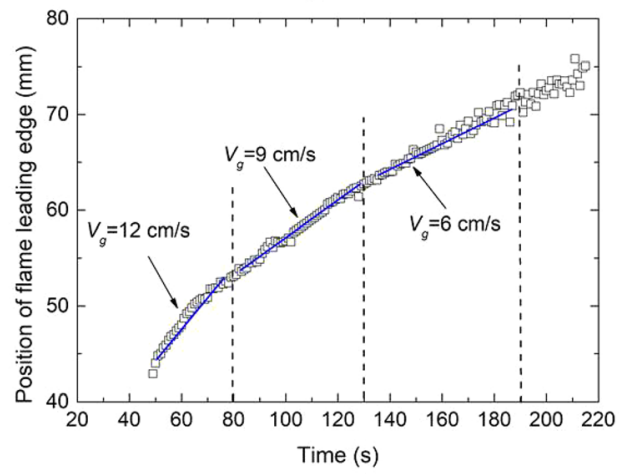

Figure 8. The track of position via video camera for the flame leading edge on PMMA rod as a function of time at a $X_{02}=33.5 \%$, and $b X_{02}=49.4 \%$.

\section{ELECTRONIC SUPPLEMENTARY MATERIAL}

The online version of this article (https://doi.org/10.1007/s10694-019-00896-8) contains supplementary material, which is available to authorized users.

\section{References}

1. Friedman R (1996) Fire safety in spacecraft. Fire Mater. https://doi.org/10.1002/(SIC I)1099-1018(199609)20:5\%3c235::AID-FAM580\%3e3.0.CO;2-Y

2. Urban DL, Ferkul P, Olson S et al (2018) Flame spread: effects of microgravity and scale. Combust Flame 199:1-22. https://doi.org/10.1016/j.combustflame.2018.10.012 
3. Thomsen M, Huang X, Fernandez-Pello C et al (2019) Concurrent flame spread over externally heated Nomex under mixed convection flow. Proc Combust Inst 37:38013808. https://doi.org/10.1016/j.proci.2018.05.055

4. Ferkul PV, Bhattacharjee S, Fernandez-pello C et al (2014) Combustion of solids in microgravity: results from the BASS-II experiment

5. Link S, Huang X, Fernandez-Pello C et al (2018) The effect of gravity on flame spread over PMMA cylinders. Sci Rep 8:120. https://doi.org/10.1038/s41598-017-18398-4

6. Olson SL, Ferkul PV (2017) Microgravity flammability boundary for PMMA rods in axial stagnation flow: experimental results and energy balance analyses. Combust Flame 180:217-229. https://doi.org/10.1016/j.combustflame.2017.03.001

7. ASTM (2010) Standard test method for measuring the minimum oxygen concentration to support candle-like combustion of plastics (Oxygen Index)

8. Fujita O (2015) Solid combustion research in microgravity as a basis of fire safety in space. Proc Combust Inst 35:2487-2502. https://doi.org/10.1016/j.proci.2014.08.010

9. Fernandez-Pello AC, Ray SR, Glassman I (1978) Downward flame spread in an opposed forced flow. Combust Sci Technol 19:19-30. https://doi.org/10.1080/ 00102207808946860

10. Sibulkjn M, Lee CK (1974) Flame propagation measurements and energy feedback analysis for burning cylinders. Combust Sci Technol 9:137-147. https://doi.org/10.1080/ 00102207408960349

11. Higuera FJ, Liñán A (1999) Flame spread along a fuel rod in the absence of gravity. Combust Theory Model 3:259-265. https://doi.org/10.1088/1364-7830/3/2/003

12. Delichatsios MA, Altenkirch RA, Bundy MF et al (2000) Creeping flame spread along fuel cylinders in forced and natural flows and microgravity. Proc Combust Inst 28:2835-2842. https://doi.org/10.1016/S0082-0784(00)80706-7

13. Tarifa CS, Corchero G, Juste GL (1988) An experimental programme on flame spreading at reduced gravity conditions. Appl Microgravity Technol I:165-169

14. Salva JJ, Juste GL (1991) Gravitational effects on flame spreading over thin cylindrical fuel samples. Microgravity Sci Technol 4:191-198

15. Huang X, Link S, Rodriguez A et al (2019) Transition from opposed flame spread to fuel regression and blow off: effect of flow, atmosphere, and microgravity. Proc Combust Inst 37:4117-4126. https://doi.org/10.1016/j.proci.2018.06.022

16. Kobayashi Y, Terashima K, bin Borhan MAF, Takahashi S (2019) Opposed flame spread over polyethylene under variable flow velocity and oxygen concentration in microgravity. Fire Technol . https://doi.org/10.1007/s10694-019-00862-4

17. Nakamura Y, Kizawa K, Mizuguchi S et al (2016) Experimental study on near-limiting burning behavior of thermoplastic materials with various thicknesses under candle-like burning configuration. Fire Technol 52:1-25. https://doi.org/10.1007/s10694-016-0567-5

18. Williams FA (1977) Mechanisms of fire spread. Symp Combust 16:1281-1294. https:// doi.org/10.1016/S0082-0784(77)80415-3

19. Kobayashi Y, Huang X, Nakaya S et al (2017) Flame spread over wires: the role of dripping and core. Fire Saf J 91:112-122. https://doi.org/10.1016/j.firesaf.2017.03.047

20. Kobayashi Y, Konno Y, Huang X et al (2018) Effect of insulation melting and dripping on opposed flame spread over laboratory simulated electrical wires. Fire Saf J 95:1-10. https://doi.org/10.1016/j.firesaf.2017.10.006

21. Nakamura Y, Azumaya K, Ito H, Fujita O (2009) Flame spread over electric wire in space environment: steady or unsteady? In: Kozo Saito, Ito A, Nakamura Y, Kuwana K (eds) Proceedings of 27 th international symposium on space technology and science. Springer, Tsukuba, Japan 
22. Takeuchi H, Fujita O, Nakamura Y et al (2012) Study on unsteady molten insulation volume change during flame spreading over wire insulation in microgravity. Proc Combust Inst 34:2657-2664. https://doi.org/10.1016/j.proci.2012.06.158

23. Hu WR, Zhao JF, Long M et al (2014) Space program SJ-10 of microgravity research. Microgravity Sci Technol 26:159-169. https://doi.org/10.1007/s12217-014-9390-0

24. Zhao H, Qiu J, Tang B et al (2016) The SJ-10 recoverable microgravity satellite of China. J Space Explor 4:1-9

25. Zhu F, Wang S, Lu Z (2018) A comparative study of near-limit flame spread over a thick solid in space- and ground-based experiments. Microgravity Sci Technol 30:943949. https://doi.org/10.1007/s12217-018-9655-0

26. Zhu F, Lu Z, Wang S, Yin Y (2019) Microgravity diffusion flame spread over a thick solid in step-changed low-velocity opposed flows. Combust Flame 205:55-67. https:// doi.org/10.1016/j.combustflame.2019.03.040

27. Joeckle R, Gautier B, Lacroix F et al (1992) Behaviour of different PMMA qualities under $\mathrm{CO}_{2}$ laser irradiation. SPIE 1810:624-627

28. Olson SL, Hegde U, Bhattacharjee S et al (2004) Sounding rocket microgravity experiments elucidating diffusive and radiative transport effects on flame spread over thermally thick solids. Combust Sci Technol 176:557-584. https://doi.org/10.1080/ 00102200490276773

29. Prasad K, Nakamura Y, Olson SL et al (2002) Effect of wind velocity on flame spread in microgravity. Proc Combust Inst 29:2553-2560

30. Burke SP, Schumann TEW (1928) Diffusion flames. Ind Eng Chem 20:998-1004. https://doi.org/10.1021/ie50226a005

31. Williams FA (1985) Combustion theory, 2nd edn. CRC Press, Boca Raton

32. Nakamura Y, Yoshimura N, Ito H et al (2009) Flame spread over electric wire in subatmospheric pressure. Proc Combust Inst 32:2559-2566. https://doi.org/10.1016/ j.proci.2008.06.146

33. Lin K-C, Faeth G-M (1996) Effects of hydrodynamics on soot formation in laminar opposed-jet diffusion flames. J Propuls Power 12:691-698. https://doi.org/10.2514/ 3.24090

34. Xiao H, Gollner MJ, Oran ES (2016) From fire whirls to blue whirls and combustion with reduced pollution. Proc Natl Acad Sci 113:9457-9462. https://doi.org/10.1073/ pnas. 1605860113

35. Fuentes A, Legros G, Claverie A et al (2007) Interactions between soot and $\mathrm{CH}^{*}$ in a laminar boundary layer type diffusion flame in microgravity. Proc Combust Inst 31(II):2685-2692. https://doi.org/10.1016/j.proci.2006.08.031

36. Bhattacharjee S, Ayala R, Wakai K, Takahashi S (2005) Opposed-flow flame spread in microgravity-theoretical prediction of spread rate and flammability map. Proc Combust Inst 30:2279-2286. https://doi.org/10.1016/j.proci.2004.08.020

37. Tien JS, Bedir H (1997) Radiation extinction of diffusion flames - a review. In: AsianPacific Conference on Combustion. Osaka, Japan

38. Taylor P, Kumar C, Kumar A (2012) Combustion theory and modelling on the role of radiation and dimensionality in predicting flow opposed flame spread over thin fuels. Combust Theory Model 16:37-41. https://doi.org/10.1080/13647830.2011.642003

39. Olson SL (1991) Mechanisms of microgravity flame spread over a thin solid fuel: oxygen and opposed flow effects. Combust Sci Technol 76:233-249. https://doi.org/10.1080/ 00102209108951711

40. Kikuchi M, Fujita O, Ito K et al (1998) Experimental study on flame spread over wire insulation in microgravity. Symp Combust 27:2507-2514. https://doi.org/10.1016/S00820784(98)80102-1 
41. West J, Tang L, Altenkirch RA et al (1996) Quiescent Flame Spread Over Thick Fuels in Microgravity. 26:1335-1343. https://doi.org/10.1016/S0082-0784(96)80352-3

42. Altenkirch RA, Tang L, Sacksteder K et al (1998) Inherently unsteady flame spread to extinction over thick fuels in microgravity. Symp Combust 27:2515-2524. https:// doi.org/10.1016/S0082-0784(98)80103-3

43. Vietoris T, Ellzey JL, Joulain P et al (2000) Laminar diffusion flame in microgravity: the results of the minitexus 6 sounding rocket experiment. Proc Combust Inst 28:28832889. https://doi.org/10.1016/S0082-0784(00)80712-2

44. Fernandez-Pello AC, Ray SR, Glassman I (1981) Flame spread in an opposed forced flow: the effect of ambient oxygen concentration. Symp Combust 18:579-589. https:// doi.org/10.1016/S0082-0784(81)80063-X

45. Fernandez-Pello AC (1995) The solid phase. In: Combustion fundamentals of fire. Academic Press, San Diego, pp 31-100

46. Fujita O, Kyono $\mathrm{T}$, Kido $\mathrm{Y}$ et al (2011) Ignition of electrical wire insulation with short-term excess electric current in microgravity. Proc Combust Inst 33:2617-2623. https://doi.org/10.1016/j.proci.2010.06.123

Publisher's Note Springer Nature remains neutral with regard to jurisdictional claims in published maps and institutional affiliations. 